\title{
Anterior Tibial Vein
}

National Cancer Institute

\section{Source}

National Cancer Institute. Anterior Tibial Vein. NCI Thesaurus. Code C32115.

The vein that runs parallel to the anterior tibial artery and empties into the popliteal vein. 